\title{
O (des)interesse no amor romântico em tempos de aplicativos de paquera ${ }^{1}$
}

\author{
Ricardo Fernandes \\ Doutorando; Universidade Federal do Rio Grande do Sul, Porto Alegre, RS, Brasil \\ fernandesricardo86@gmail.com
}

Patrícia Rakel de Castro Sena

Doutora; Universidade Federal do Maranhão, São Luís, MA, Brasil rakeldecastro@gmail.com

\section{Resumo}

O impacto dos aplicativos de paquera na vida de seus usuários orientou o entendimento de que a solidez, a segurança e a monogamia, valores basilares do amor romântico, fragmentaram-se frente às mudanças tecnológicas e à individualização desenfreada. A proposta deste artigo funda-se em explorar o desinteresse de usuários desses aplicativos em relações duradouras. Para tal, foi feita uma análise de conteúdo dos comentários feitos na campanha "Seu amor de verdade" na fanpage do aplicativo "Par Perfeito" no Facebook. Como mediadores de interesses individuais, o estudo revelou que os usuários manifestam um interesse velado na busca dessa modalidade de relacionamento através de reclamações ou lamentações.

\section{Palavras-chave}

Desinteresse. Amor romântico. Análise de conteúdo. Par Perfeito. Facebook.

\section{Introdução}

A revolução tecnológica digital na contemporaneidade tem papel importante na remodelação de diversas práticas sociais. Em outros tempos, a conquista, o cortejo e o

\footnotetext{
${ }^{1}$ Estudo prévio com o título Seu amor de verdade: uma análise de conteúdo sobre a percepção do amor na Fanpage do aplicativo "Par Perfeito" (FERNANDES, 2018) foi apresentado no DT Comunicação Multimídia no XXIII Congresso de Ciências da Comunicação na Região Sudeste (Intercom Sudeste 2018), realizado na Universidade FUMEC (Fundação Mineira de Educação e Cultura, Belo Horizonte), entre os dias 7 e 9 de junho de 2018.
} 
namoro, para assim começar, essencialmente tinham de ocorrer em um determinado momento no tempo e no espaço, em que os parceiros pudessem se encontrar, interagir face a face e, assim, construir laços. Hoje, em tempos nos quais os smartphones são extensões do corpo humano, além da posição central que ocupam as redes sociais, os aplicativos e outras plataformas de comunicação ubíquas no cotidiano das pessoas, o amor romântico vê-se em um novo contexto nada favorável para a sua completude, conforme os adeptos do paradigma líquido de Bauman (2004) defendem.

A visão do sociólogo polonês Bauman (2004) foi preponderante para o surgimento do argumento do presente artigo: o suposto desinteresse em valores como monogamia, compromisso e outros que correspondem ao amor romântico. No momento em que os algoritmos das plataformas digitais passam a mediar amorosamente a sociedade, os aplicativos de paquera ascendem como tendência nas práticas amorosas e sexuais. Assim, as pessoas passam a cultuar práticas ditas mais efêmeras, líquidas. 0 individualismo e o consumismo exacerbados, que assolam a modernidade líquida, são manifestados nessas plataformas, que condicionam seus usuários a usar uns aos outros, focados em prazeres momentâneos. 0 argumento do desinteresse em relações compromissadas passou a ser reproduzido pelos estudos, propagando, assim, a generalidade de um imperativo do gozo (CASTRO, 2014) e a consequente ideia de que o amor romântico não tem mais espaço na realidade atual. Por meio do apoio em uma revisão bibliográfica de periódicos brasileiros, atestou-se a recorrência da adoção do paradigma líquido para pensar o amor na atualidade, bem como a carência de estudos empíricos sobre o amor romântico na atualidade.

A proposta do presente artigo funda-se, portanto, em discutir o assertivo desinteresse dos sujeitos no amor romântico. Será que usuários de plataformas de paquera só estão interessados em sexo? Valores como monogamia, fidelidade e compromisso não têm mais espaço na realidade atual? Para dar sustentação teórico-metodológica aos questionamentos propostos, apoiou-se em Bardin (2004), Krippendorf (2012) e Recuero (2009), a fim de ser possível produzir uma análise de conteúdo da campanha do Dia dos Namorados do aplicativo "Par Perfeito" na rede social Facebook. A campanha "Seu amor de verdade" foi escolhida em função de sua associação com a problemática apresentada, sobretudo por incitar os seguidores da página a inferir opiniões, expectativas e experiências sobre o tema, fornecendo subsídios para averiguar o possível desinteresse.

Esse percurso organiza-se, pois, a partir da exploração das bases do desinteresse no amor romântico, crítica lançada por Bauman (2004), e da forma que os estudos mais 
recentes o adotam como paradigma, conforme resgate bibliográfico feito em periódicos brasileiros entre os anos de 2013 e 2017 (FERNANDES; ALMEIDA, 2018). Posteriormente, apresentamos a análise de conteúdo. Com base no que foi dito pelos usuários, diagnosticouse que o desinteresse por relações sólidas se mostra equivocadamente generalista, uma vez que os usuários manifestam, de maneira recalcada, um desejo dessa modalidade de relacionamento em meio a incentivos e reclamações.

\section{A emergência do desinteresse}

Para que possamos compreender os argumentos que fundamentam os estudiosos que defendem o desinteresse contemporâneo pelo amor romântico, um primeiro movimento consiste em apresentar como esse é definido. Ao desenvolver a Teoria da Estruturação, o sociólogo Anthony Giddens, uma das primeiras referências encontradas sobre o assunto, orienta a considerar o amor enquanto uma prática social que, para ser compreendida, deve ser analisada paralelamente "[...] a vários conjuntos de influências que afetaram as mulheres a partir do século XVIII." (GIDDENS, 1993, p. 52). Para Giddens (1993), o surgimento do amor romântico resultou em uma modalidade de relacionamento tida como pura, pautada essencialmente pelo sentimento dos envolvidos. A ideia desse tipo de relação eclodiu no final do século XVIII, concomitantemente a uma onda crescente de produtos melodramáticos massivos, que acabaram servindo como verdadeiros manuais em um contexto materializado no Romantismo enquanto movimento artístico, político e filosófico. Ao estabelecer o compromisso mútuo por meio de laços emocionais duradouros, essa modalidade de amor pode ser encarada como um movimento ativo e radical contra o machismo na sociedade moderna, sobretudo se considerarmos os padrões vigentes. Em um contexto em que grande parte das relações amorosas eram forjadas essencialmente em função de demandas econômicas, políticas e sociais, as narrativas apresentadas acabavam sendo engrenagens importantes para alimentar e satisfazer o imaginário e as expectativas afetivas dos consumidores. Nesse sentido, “[...] a realidade das histórias românticas era uma expressão de fraqueza, uma incapacidade de se chegar a um acordo com a auto-identidade frustrada da vida social real." (GIDDENS, 1993, p. 55). Sua produção era, e permanece sendo, um discurso de esperança, um local de fuga do cotidiano, a inspiração para uma vida feliz e realizada. 
Juntamente com outras mudanças sociais, a difusão de ideias de amor romântico estava profundamente envolvida com transições importantes que afetaram o casamento e também outros contextos da vida pessoal. 0 amor romântico presume algum grau de autoquestionamento. Como eu me sinto em relação ao outro? Como o outro se sente a meu respeito? Será que os nossos sentimentos são 'profundos' o bastante para suportar um envolvimento prolongado? (GIDDENS, 1992, p. 56).

Na psicologia, Nathaniel Branden (1982) propõe pensar o amor romântico a partir de vetores como a intimidade, a vulnerabilidade e o envolvimento como princípios de uma ligação emocional intensa, bases para a experiência. Em outras palavras, o psicoterapeuta entende amor romântico como "[...] um vínculo passional espiritual-emocional-sexual entre um homem e uma mulher que reflete o profundo respeito pelo valor do outro [...]" (BRADEN, 1982, p. 19). A definição produzida pelo autor está ancorada na relação entre a história sobre o amor, a cultura e suas experiências como psicoterapeuta e conselheiro matrimonial. Nesse último aspecto, Branden (1982) aproxima-se do sujeito, de sua prática cotidiana e de suas expectativas para buscar a raiz desse tipo de prática. A abordagem de Branden (1982) é uma possibilidade de reflexão nos dias atuais: considerando o amor romântico uma necessidade, uma expectativa real, uma prática social que se ressignifica com o passar do tempo, que tipo de experiência temos hoje? Quais expectativas buscamos satisfazer por meio dele? Para Braden (1982), a resposta está na maneira como o encaramos: é preciso apreender o amor romântico enquanto um objeto de pesquisa, como ele de fato é e como de fato está acontecendo.

Precisamos vê-lo em si mesmo, como o encontro sem paralelo entre um homem e uma mulher, uma experiência e uma aventura sem par possível, mas não necessariamente envolvendo filhos; possível, mas não necessariamente envolvendo exclusividade sexual; possível, mas não necessariamente envolvendo 'até que a morte nos separe'. (BRANDEN, 1982, p. 64).

Contrariamente, Zygmunt Bauman (2004) considera inviável pensar o amor romântico tal como Branden (1982) propõe - desvinculado de valores como o compromisso e fidelidade mútua. Na visão do sociólogo, o amor romântico morreu em função da exacerbação do individualismo e do consumismo, ambos apontados como vetores responsáveis pela fragmentação social e, claro, pelo nascimento de relações amorosas tidas 
como frágeis (BAUMAN, 2004). Então, ao atestar que as relações tendem a ser menos frequentes e duradouras, o autor (2004) dá ideia de que a causa reside no estado de liquidez em que instâncias, campos e responsabilidades sociais - ou melhor, a modernidade de modo mais geral - encontram-se. Com isso, instalou-se, no indivíduo, uma insegurança, um medo contemporâneo que suscita a coabitação conflitante da vontade de estreitar laços e "[...] ao mesmo tempo mantê-los frouxos [...]" (BAUMAN, 2004, p. 4). Assim, a fidelidade e a cumplicidade de uma relação estável se convertem em demandas afetivas dispersas em várias experiências avulsas. Neste sentido, o autor (2004) elucida:

[...] a definição romântica do amor como 'até que a morte nos separe' está decididamente fora de moda, tendo deixado para trás seu tempo de vida útil em função da radical alteração das estruturas de parentesco às quais costumava servir e de onde extraia seu vigor e sua valorização. Mas o desaparecimento dessa noção significa, inevitavelmente, a facilitação dos testes pelos quais uma experiência deve passar a ser chamada de 'amor': Em vez de haver mais pessoas atingindo experiências às quais nos referimos com a palavra amor expandiu-se muito. Noites avulsas de sexo são referidas pelo codinome de 'fazer amor' [...] (BAUMAN, 2004, p. 10).

É precisamente nesse ponto que Bauman (2004) sustenta o seu argumento sobre o desinteresse social em relacionamentos sólidos, ou melhor, a morte do amor romântico e a emergência de uma prática afetiva mais apropriada à realidade atual, considerada mais efêmera, líquida. Isso se dá, na visão de Bauman (2004), porque os parceiros amorosos se tratam como mercadorias prontas para serem consumidas e descartadas após o uso. As plataformas de redes sociais e aplicativos de paquera exemplificam essa realidade ao apresentar indivíduos como verdadeiros itens de vitrines. A linha de pensamento do sociólogo serviu de paradigma para diversos trabalhos na área, como mostram as publicações publicadas em periódicos qualis A2 e B1 na área de Comunicação e Informação entre os anos de 2013 e 2017 (FERNANDES; ALMEIDA, 2018). Em um universo de cinco trabalhos encontrados sobre amor e plataformas digitais, dois destacam-se por utilizar Bauman (2004) em suas referências.

Como boa parte dos estudos sobre o assunto no Brasil, Castro (2014) segue o pensamento de Bauman (2004), argumentando que o amor e o casamento deixam de ser condições um para o outro, cedendo lugar para "[...] àquilo que Giddens (1993) chama de 'amor confluente', e Bauman (2004) denomina 'amor líquido'." (CASTRO, 2014, p. 79). 
Ambos os casos contrastam o caráter eterno de sua matriz romântica, uma vez que estão sujeitos à conveniência dos parceiros. A autora (2014) acrescenta, ainda, que a qualidade romântica do amor, largamente disseminada pela indústria cultural, perde a razão de ser na atualidade, uma vez que se ampara, essencialmente, em um cenário no qual a fantasia romântica é suprida pela mesma indústria que a fabricou. Com o advento da cibercultura, na qual o usuário é agenciador de si, a fantasia como modelo e ideal a ser seguido não tem muito espaço. Em seu lugar, surge um imperativo do gozo, "[...] menos dependente de balizas exteriores trazidas pela fantasia [...]" (CASTRO, 2014, p. 80), algo que as plataformas de paquera colaboram em realizar.

Maia e Bianchi (2014), por outro lado, atestam que o uso de aplicativos de paquera pode, sim, desenvolver outras modalidades de laços sociais. Ao discutirem a cidade e a cultura contemporânea, averiguam a forma como os sujeitos atribuem elementos simbólicos e ressignificam espaços e "[...] territorialidades que refletem a emoção e a sensibilidade do estar-junto." (MAIA; BIANCHI, 2014, p. 172). Plataformas como Grindr e Scruff são verdadeiras aliadas na formação e no desenvolvimento de vínculos afetivos, sejam eles amizades, meros encontros, sexo ou namoro. Ainda que sejam, a priori, utilizadas para "pegação", essas podem gerar diferentes usos e apropriações que dependem do interesse afetivo dos usuários. De fora, as relações podem parecer superficiais em relação à compreensão do amor romântico, mas nem de longe, dizem os autores, são menos intensas, como demonstram os relatos de seus depoentes.

As tecnologias móveis possibilitam conectar-se com alguém que está em uma rodovia, passando a poucos quilômetros dentro de um ônibus e descobrir um novo romance. Em uma entrevista, José contou que estava em uma viagem para descansar. Em determinada hora de sua viagem, decidiu ficar on-line em seu perfil do aplicativo Grindr e começou a conversar com outro usuário, que estava voltando para a mesma cidade de José, Rio de Janeiro. A conversa fluiu bem, dias depois marcaram um encontro, houve reconhecimento pelos gostos, o sexo foi bom e, pouco depois começaram a namorar. 'Esse brinquedinho é ótimo [...] funciona super bem'. (MAIA; BIANCHI, 2014, p. 180).

Como se vê, a exemplo de aplicativos destinados ao público gay e com recorrente uso voltado para encontro de parceiros sexuais, conforme os próprios autores dizem, esses também podem ser usados para a formação de outros tipos de envolvimento. Desse modo, o 
argumento de que usuários de aplicativos estão sempre na expectativa do próximo parceiro, sem interesse de desenvolver relações sólidas, parece soar demasiadamente generalista.

\section{0 (des)interesse no amor romântico: análise de conteúdo}

Com a missão de promover encontros românticos, o aplicativo "Par Perfeito" trata-se de uma das plataformas desenvolvidas pelo grupo Match.com. Segundo Rüdiger (2013), o grupo norte-americano começou sendo um dos pioneiros na mediação de relações afetivas, iniciando suas atividades em 1995. Dois anos depois, no Brasil, desenvolveu suas primeiras experiências com o site Almas Gêmeas, veiculado no portal Terra, e o site Amigos Virtuais do portal Uol. Desde sua fusão com outras empresas, o agora conglomerado InterActive passa a administrar vários serviços de paquera online. 0 "Par Perfeito" nasce, oficialmente, como um site nos anos 2000. De acordo com o Google Play, a versão mobile atingiu a marca de mais de um milhão de downloads.

Com mais de um milhão de seguidores, a fanpage da plataforma "Par Perfeito" no Facebook mostrou-se ativa na produção de conteúdos e engajamento. Exemplo disso é a campanha em comemoração do dia dos Namorados, "Seu amor de verdade". As redes sociais do aplicativo, durante todos os dias do mês de junho de 2017, postaram conteúdos objetivando promover a conversação sobre o amor, bem como o uso da plataforma para a busca de parceiros amorosos. A proposta da campanha, portanto, alinha-se ao objetivo do presente artigo, fornecendo dados para a investigação. Antes, contudo, faz-se necessário apresentar a análise de conteúdo enquanto instrumento analítico e apresentar os procedimentos metodológicos adotados.

\subsection{Procedimentos metodológicos}

A apreensão dos sujeitos, suas expectativas e a forma como percebem as relações amorosas em tempos de aplicativos de paquera tratam-se de dados fundamentais para a avaliação do desinteresse pelo amor romântico, argumento esse lançado teoricamente pelas referências deste estudo. Assim, buscamos mapear como os usuários concebem o amor a partir da análise de conteúdo de seus relatos na campanha "Seu amor de verdade". Designada como um “[...] conjunto de técnicas de análise das comunicações, que utiliza de 
procedimentos sistemáticos e objetivos de descrição de conteúdo das mensagens [...]" (BARDIN, 2004, p. 38), a análise de conteúdo trata-se de um método capaz de orientar o estudo dos vestígios deixados pelos usuários em suas interações com a fanpage. Para melhor identificação das temáticas oriundas nos comentários, Bardin (2004) sugere o lançamento de questões diretas. Em nosso caso, são elas: (1) Quais as recorrências ditas em relação ao amor? (2) Quais as expectativas? (3) Há registros de desinteresse? Como se manifestam?

Ao considerar a consequente inferência e interpretação dos dados coletados, Krippendorf (2012) adverte a necessidade de considerar o contexto em que os relatos são produzidos, do mesmo modo que os atores que os produzem. Sendo o Facebook uma plataforma de sociabilidade, na qual residem "[...] representações e extensões do espaço social dos atores [...]" (RECUERO, 2009, p. 29) no espaço online. Boyd (2010) caracteriza esse espaço como um lugar em que as informações perduram, replicam e são propagadas com visibilidade escalada e buscável, delineando, portanto, a dinâmica do âmbito digital e suas interações. Particularmente, em nossa proposta, esse contexto colaborou nos processos que envolvem a coleta de dados feita manualmente entre os meses de junho e julho de 2017.

No que tange à estruturação, Bardin (2004) diz que a análise de conteúdo se funda em três grandes fases: a pré-análise, quando se sistematizam as premissas iniciais lançadas pelo referencial teórico e pelos indicadores para interpretar os dados coletados; a exploração do material e seu tratamento, ou seja, procedimentos voltados para a codificação e recorte dos textos em unidades de registros capazes de gerar contagens e classificações em categorizações temáticas; e, por fim, a inferência e interpretação dos dados, voltados a analisar os conteúdos manifestos, os temas latentes e recorrentes nos dados coletados.

\subsection{Análise de conteúdo da campanha "Seu amor de verdade"}

Com a missão de organizar os dados, o primeiro momento da análise de conteúdo abarcou procedimentos de exploração e seleção dos dados da campanha "Seu amor de verdade". Na comemoração do Dia dos Namorados, a fanpage do aplicativo "Par Perfeito" postou 36 peças $^{2}$ durante o mês de junho de 2017. Essas produções dividiam-se em cartazes, GIFs - Graphics Interchange Format, histórias de sucesso com o uso da \#DeuCerto, dicas da plataforma com o uso da \#DicasDoPP, vídeos e a propagação de um artigo

\footnotetext{
2 A partir da observação da fanpage, contabilizou-se no mês de Junho um total de 36 peças, entre as quais, a maioria (77,78\%) foram cartazes.
} 
especialmente produzido para o blog do aplicativo. 0 contato com o material produzido na campanha permitiu atestar que as peças incitavam os usuários a discutir sobre o amor. Entre elas, os cartazes despertavam maior frequência de interatividade, algo que se reflete no número de curtidas e compartilhamentos, critérios esses que pautaram a seleção das peças para análise dos comentários.

Quadro 1 - Monitoramento da campanha "Seu amor de verdade"

\begin{tabular}{|c|c|c|c|c|c|c|c|}
\hline Data & Peça & Curtidas & Compartilhamento & Data & Peça & Curtidas & Compartilhamento \\
\hline 01/06 & Cartaz & 195 & 26 & $02 / 06$ & Cartaz & 376 & 192 \\
\hline 03/06 & Cartaz & 172 & 32 & $04 / 06$ & Cartaz & 281 & 140 \\
\hline $05 / 06$ & Cartaz & 159 & 36 & $06 / 06$ & Cartaz & 248 & 103 \\
\hline $07 / 06$ & Cartaz & 126 & 23 & 08/06 & Cartaz & $8,3 \mathrm{mil}$ & 365 \\
\hline $08 / 06$ & \#DicasDoPP & 83 & - & $09 / 06$ & \#DeuCerto & 176 & 2 \\
\hline 09/06 & Artigo Blog & 83 & 1 & $10 / 06$ & Cartaz & 341 & 155 \\
\hline $11 / 06$ & Cartaz & 113 & 21 & $12 / 06$ & Gif & 88 & 16 \\
\hline $12 / 06$ & Vídeo & 112 & 32 & $13 / 06$ & Cartaz & 162 & 23 \\
\hline $14 / 06$ & Cartaz & 409 & 155 & $15 / 06$ & \#DicasDoPP & 184 & 14 \\
\hline $16 / 06$ & Cartaz & 218 & 34 & $17 / 06$ & Cartaz & 428 & 486 \\
\hline $18 / 06$ & Cartaz & 183 & 21 & $19 / 06$ & Cartaz & 178 & 16 \\
\hline $20 / 06$ & Cartaz & 279 & 130 & $21 / 06$ & \#DicasDoPP & 48 & 11 \\
\hline $22 / 06$ & Cartaz & 114 & 13 & $23 / 06$ & Cartaz & 142 & 29 \\
\hline $24 / 06$ & Cartaz & 375 & 128 & $25 / 06$ & Cartaz & 284 & 90 \\
\hline $26 / 06$ & Cartaz & 276 & 82 & $27 / 06$ & Cartaz & 212 & 68 \\
\hline $28 / 06$ & Cartaz & 389 & 161 & $29 / 06$ & \#DeuCerto & 152 & - \\
\hline $29 / 06$ & Cartaz & 114 & - & $29 / 06$ & Cartaz & 55 & - \\
\hline $30 / 06$ & Cartaz & 131 & 16 & $30 / 06$ & Cartaz (encerramento) & 73 & - \\
\hline
\end{tabular}

Fonte: Elaborado pelos autores.

Considerando a alta interatividade dos usuários na fanpage, a exequibilidade da análise de conteúdo foi o que justificou a seleção de três postagens, uma vez que essas foram analisadas manualmente. A seleção das peças deu-se pelo critério de quantidade de curtidas, já que, de modo geral, todos os comentários inferidos nas peças tinham pertinência com o 
foco de nosso estudo. Publicadas nos dias 8 de junho 2017, 14 de junho 2017 e 17 de junho 2017, a primeira peça conquistou 8,3 mil curtidas, a segunda, 409, e a terceira, 428. Para a análise de conteúdo, os três cartazes reuniram um universo de 326 comentários ${ }^{3}$.

Figura 1 - Seleção de peças da campanha "Seu amor de verdade"

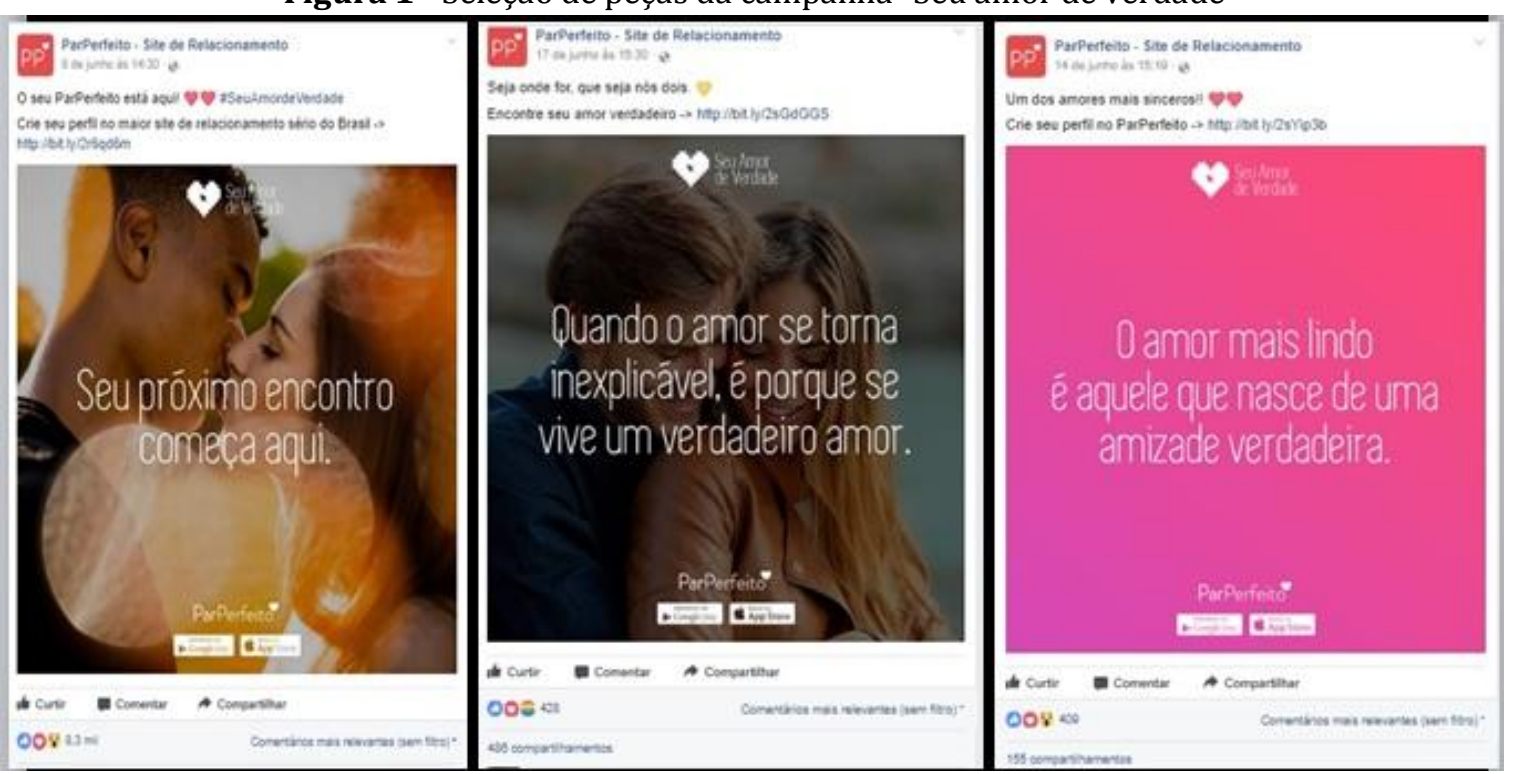

Fonte: Adaptado pelos autores da fanpage “Par Perfeito" do Facebook (PARPERFEITO, 2018).

A exploração do material, em um segundo momento, fundou-se em organizar os dados em estruturas. Os 326 comentários das peças selecionadas foram estudados com o auxílio de planilhas produzidas manualmente e online pelos autores. Migrar esses dados para a planilha auxiliou na percepção de um panorama mais geral do que foi dito pelos usuários e na consequente observação da recorrência de palavras e argumentos. A relevância com a proposta da pesquisa, refletida nas questões diretas lançadas ${ }^{4}$, foi o que pautou a seleção dos 126 comentários que constituíram o corpus da análise5. 0 contato com os dados tornou possível perceber certas tendências argumentativas sobre o amor, manifestadas pela recorrência de palavras e frases-temas. Essas recorrências refletem, segundo Bardin (2004), a repetição de temáticas que foram recortadas em unidades capazes de serem comparadas, categorizadas, e diferenciadas. Organizamos essas unidades nas categorias: expectativa/procura; aconselhamentos/incentivos; e reclamações/lamentações. As

\footnotetext{
3 Ainda que o número de curtidas, compartilhamentos e comentários das peças foram coletados manualmente entre os meses de junho e julho de 2017, é preciso lembrar que, como bem nos diz Boyd (2010), esses dados podem aumentar frente à dinâmica do contexto em que as informações se encontram.

4 (1) Quais as recorrências ditas em relação ao amor? (2) Quais as expectativas? (3) Há registros de desinteresse?

5 Flertes, comentários sobre a beleza dos participantes e conversações aleatórias entre usuários ilustram o teor dos comentários que foram desconsiderados para o corpus de análise.
} 
subcategorizações dessas, o seu número de frequência, as palavras e frases-tema recorrentes foram sistematizados no quadro abaixo.

Quadro 2 - Categorização temática

\begin{tabular}{|c|c|}
\hline Categoria & Subcategoria (frequência)/frases-tema. \\
\hline $\begin{array}{l}\text { Expectativa/p } \\
\text { rocura (em } \\
\text { números: 29) }\end{array}$ & 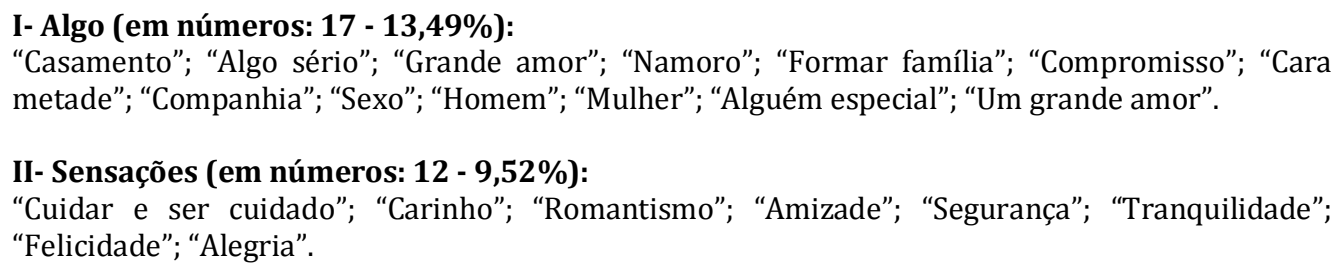 \\
\hline $\begin{array}{l}\text { Incentivos/ac } \\
\text { onselhamento } \\
\text { s (em } \\
\text { números: 39) }\end{array}$ & 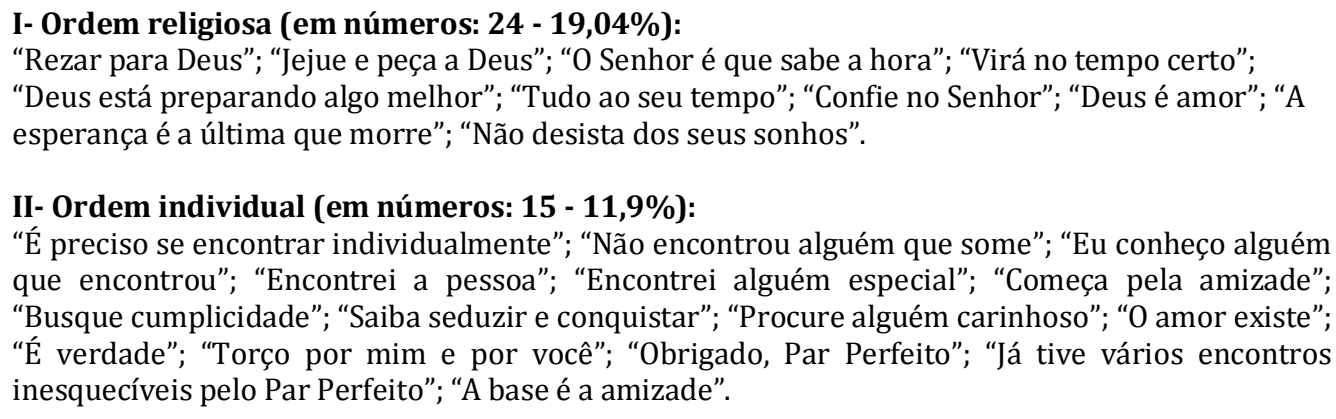 \\
\hline $\begin{array}{l}\text { Reclamações/l } \\
\text { amentações } \\
\text { (em números: } \\
\text { 58) }\end{array}$ & 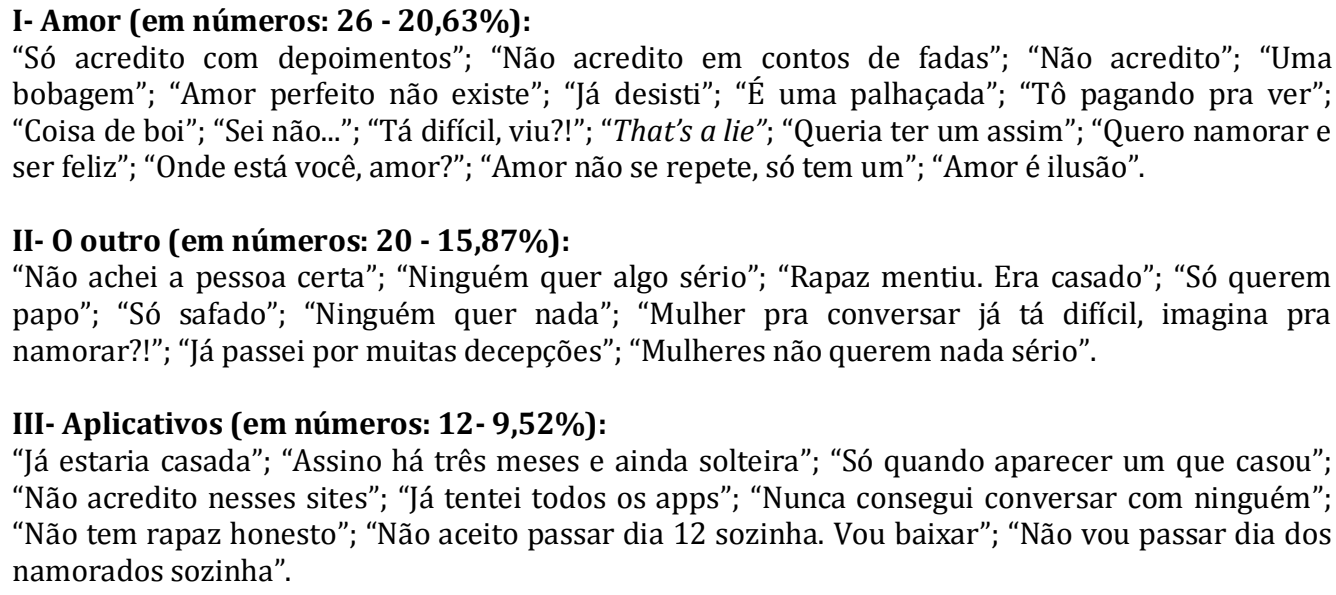 \\
\hline
\end{tabular}

Fonte: Elaborado pelos autores.

Bardin (2004) orienta que a terceira parte, a análise do conteúdo em si, funde-se em fazer inferências a partir dos dados categorizados. A análise do tipo temática soa apropriada, uma vez que busca desvendar “[...] um ou vários temas ou itens de significação, numa unidade de codificação previamente determinada [...]" (BARDIN, 2004, p. 77). A ideia é descobrir os significados por meio das recorrências de sentido que estruturam a comunicação e pela frequência da presença do que foi comunicado. A abordagem, nesse 
aspecto, torna-se interessante ao evidenciar os valores, crenças, e motivações daquele que comunica, auxiliando na constatação de tendências de sentido.

Em expectativas/procura, os comentários legitimam o amor a partir de duas frentes: a primeira como algo, uma coisa concreta; e a segunda como uma experiência repleta de sensações. Em geral, o primeiro caso demonstra uma tendência em apreendê-lo como uma relação compromissada voltada para a formação de família. Namoro, casamento, homens e mulheres tidos como especiais foram algumas das recorrências mais frequentes para representar essa coisa da qual estão em busca. No que tange às sensações, há os sentimentos ternos, tranquilos, como felicidade, alegria e prosperidade. Na visão dos usuários, o romantismo é tido como algo fraterno, com o qual os parceiros devem cuidar e serem cuidados. A expectativa dos usuários sobre o amor alinha-se à compreensão de Bauman (2004) e dos autores que o utilizam como paradigma teórico, uma vez que todos o encaram como uma modalidade de relacionamento duradouro voltado para a constituição de família, que prega valores como monogamia e fidelidade. Ao que parece, há usuários manifestando interesse nessa modalidade de relacionamento e utilizando plataformas de paquera na esperança de encontrar, também, parceiros amorosos, como pode ser evidenciado na Figura 2.

Figura 2 - Comentários Postagem 1 (08/06/2017)

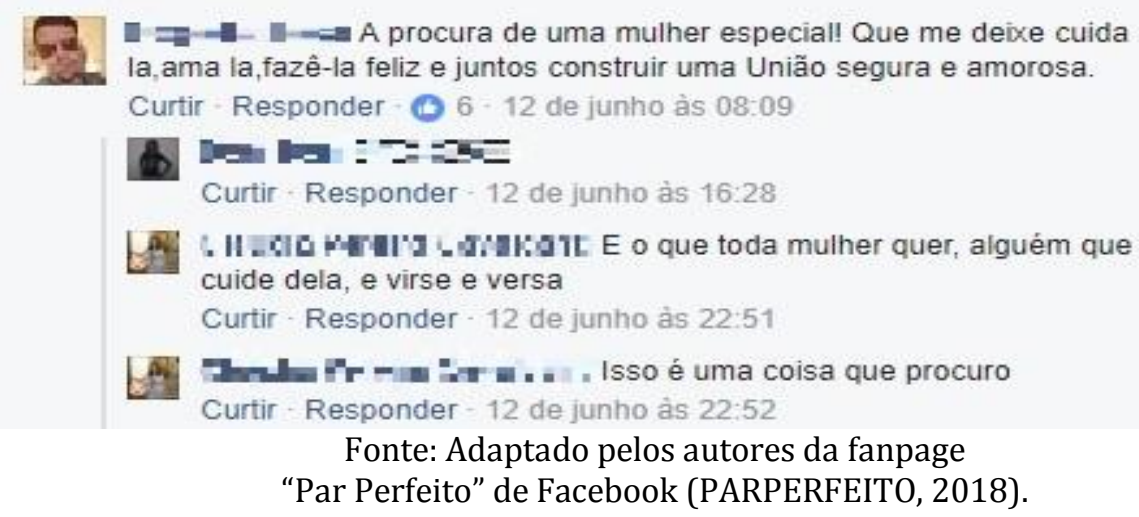

Em aconselhamentos/incentivos, votos de torcida e esperança na realização do amor estão atrelados, boa parte das vezes, a um consentimento feito por uma ordem maior: Deus. Em alguns comentários, a concretização do amor romântico, tida como um sonho a ser realizado, necessita da ajuda, aprovação ou merecimento por parte de instâncias superiores. Nesse sentido, podemos perceber a presença da força do ideal de felicidade do amor romântico como uma espécie de remédio necessário para uma vida melhor e realizada 
(GIDDENS, 1993) e também como esse ideal se condiciona a uma concessão vinda de uma ordem divina, a qual apresenta maior frequência que a outra subcategoria, a ordem individual. Nessa última, a concretização do amor é incentivada por meio de relatos de experiências próprias de usuários ou conhecidos que conquistaram o amor. Foram encontradas dicas como começar pela amizade e buscar valores como cumplicidade, carinho, além de recomendações, como saber seduzir o parceiro - mas essas ocorreram em menor grau, tendo pouca regularidade. A conquista não foi algo tão recorrente, mas foi tida como um dos pré-requisitos para o amor, assim como uma necessidade de "se encontrar" individualmente.

Figura 3 - Comentários Postagem 3 (17/06/2017)

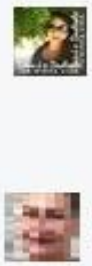

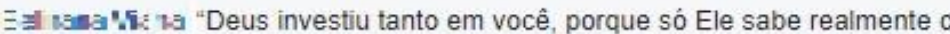
valor que você tem. Ele planejou para você um propósito especial que só você poderá realizar. Acredite, você é o melhor de Deus!"

- Padre Fábio de Melo

Curtir - Responder - 21 de junho às $21: 58$

Jiri IE Cira Dekzer quando, 0 amor éverdadeiro, nada se esplica, a todo

intante se quer fazer um carinho, dizer te amo, dar um beijo,tirar um tempo para ficar sós,passear de mão dadas deitar na grama olhar o brilho da lua das estrelas, tomar banhode mar,abraçar emfim amor se completar Curtir - Responder - 23 de junho às $22: 37$

Fonte: Adaptado pelos autores da fanpage "Par Perfeito" de Facebook (PARPERFEITO, 2018).

A última das categorias, foco maior deste estudo e com maior número de comentários (58), fornece os subsídios para identificação das manifestações de desinteresse e do modo como se manifestam. A análise dos comentários mostrou que há uma considerável frequência de manifestações de desinteresse no amor romântico, e que esse, curiosamente, manifesta-se em meio a relatos de lamentações e/ou reclamações. Os registros na categoria lamentação/reclamação apontam o desinteresse no amor em três alvos: o amor, os parceiros encontrados (o outro) e os aplicativos, resultando em suas subcategorias. No que tange à primeira subcategoria, o amor, os comentários mostram que os usuários o consideram uma mentira, uma fantasia criada para iludir. Outros, quando não questionam onde e como achá-lo, lamentam não ter um nos moldes da imagem da postagem. Lamentam, sobretudo, a falta de felicidade, essa proporcionada pela ausência do amor. Queixam-se da dificuldade de encontrá-lo e, em função disso, creem que ele seja algo distante da realidade. Nas conversações, percebe-se uma desmotivação, uma insatisfação mais geral. Os relatos foram fundamentais para que pudéssemos identificar o que motivava o desinteresse dos usuários pelo amor romântico: a crença de que essa modalidade de 
relação não possui mais espaço na realidade atual, argumento defendido por Bauman (2004) e Castro (2014). No entanto, essa crença é também um lamento que reflete a nostalgia, o desejo de encontrar um amor para toda a vida.

Quando as lamentações se voltam para o outro, a segunda subcategoria, os relatos argumentam sobre a falta de predisposição por parte dos interessados amorosos em desenvolver algo sério ou mesmo conversar. As mentiras contadas, a busca pelo sexo e as decepções amorosas foram os principais obstáculos apontados pelos usuários para conseguir "algo sério". Sobre os aplicativos, consideram que os usuários que ali trafegam não são honestos, não querem conversar, não tomam qualquer iniciativa ou acenam interesse. Sobre a possível "ajuda" desses aplicativos, os incrédulos até aceitam mudar de opinião, desde que apareçam pessoas que já foram beneficiadas por eles, como evidencia a Figura 4.

Figura 4 - Comentários Postagem 1 (08/06/2017)

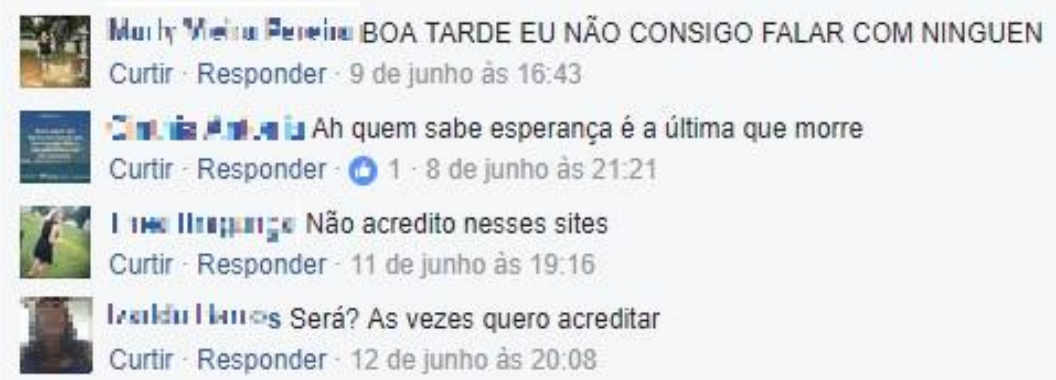

Fonte: Adaptado pelos autores da fanpage "Par Perfeito" de Facebook (PARPERFEITO, 2018).

Nas últimas subcategorias, constatamos que o desinteresse se mostra em relatos debochados, frustrados e, por vezes, revoltados. Evidencia-se, portanto, um recalque desses usuários nessa modalidade de relacionamento. Desse modo, apreendemos que as manifestações de desinteresse pelo amor romântico refletem interesses velados, sobretudo quando os usuários desafiam tanto a efetividade do aplicativo em promover o encontro com o seu par ideal quanto os outros usuários, quando esses relatam histórias de casos bemsucedidos. Em outras palavras, precisam vivenciar ou saber que pessoas próximas tiveram experiências bem-sucedidas para que o desinteresse velado se converta em um interesse declarado. 


\section{Considerações finais}

Esse percurso se mostrou que monogamia, fidelidade e compromisso seguem sendo alvos de interesse, pelo menos de uma parcela dos usuários que comentaram na campanha do Dia dos Namorados na página do aplicativo "Par Perfeito". Considerando esses espaços como extensões sociais dos atores (RECUERO, 2009), a regularidade de menções a valores do amor romântico demonstrou que esse ainda pode ser tido como ideal de felicidade nos dias atuais. Os resultados obtidos pela análise de conteúdo, portanto, destoam da crítica essencialmente unívoca e generalista de que os sujeitos, nesses espaços, voltam-se exclusivamente para forjar relações efêmeras, crítica essa lançada por Bauman (2004) e seguida como paradigma teórico por estudos como o apresentado por Castro (2014).

Mesmo os registros de desinteresse, foco desta investigação, endossam o argumento de que os usuários de aplicativos podem estar interessados em buscar relações sólidas. Outrossim, no momento em que se observam deboches, frustrações e revoltas nos comentários de desinteresse no amor romântico, atesta-se o movimento dos sujeitos de esconder uma vontade, um desejo por vezes reprimido, recalcado de uma relação duradoura e compromissada.

Recalque, para a psicologia, compreende um sentimento de defesa vindo do inconsciente contra ideias que são vistas pelo consciente do indivíduo como penosas. Uma explicação para essa reação seria um possível sentimento de deslocamento desses sujeitos nos aplicativos de paquera, tidos como lugares de promiscuidade. Os comentários analisados comprovam a apreensão pejorativa que circunscreve essas plataformas, sobretudo quando vemos relatos de que não há pessoas honestas, ou ainda os desafios lançados pelo aplicativo para comprovar que sua capacidade de promover relações sólidas, todos reunidos na subcategoria aplicativos em reclamação/lamentação. Em outras palavras, a expressão do desinteresse pelo amor soa como um mecanismo de defesa acionado por essa percepção. Outra explicação possível ancora-se no receio, no medo de decepção, de se machucar emocionalmente, expressos nos registros da subcategoria o outro. Comum a ambas as possibilidades, há o preconceito, o olhar pejorativo que os próprios usuários manifestam sobre os aplicativos de paquera - um espaço que, apesar do seu ônus, os usuários fazem uso, frequentam.

Ora, se concordamos que vivemos em um tempo no qual aplicativos de paquera participam do ritual amoroso e podem direcionar seus usuários a um "imperativo do gozo" 
(CASTRO, 2014), concordamos também que os mesmos espaços podem ser usados para forjar outras modalidades de relacionamentos. Ou seja, da mesma forma que há movimentos que as utilizam para "pegação", essas plataformas podem ser apropriadas para outras finalidades (MAIA; BIANCHI, 2014) afetivas, como a busca por parceiros amorosos para relações sólidas. Na medida que os usuários lamentam ou reclamam que o interessado amoroso não está interessado em relação compromissada, esses acabam revelando a apropriação e ressignificação dessas plataformas para o encontro de parceiros dispostos a construir relações duradouras. O compartilhamento de estratégias, dicas e experiências bem-sucedidas no Par Perfeito e em outros aplicativos, reunidas nos aconselhamentos/incentivos de ordem individual, corrobora essa apropriação.

Apesar de não terem sido utilizadas para a análise de conteúdo, não poderíamos deixar de mencionar as investidas amorosas. Aproveitando o momento de desabafo sobre desinteresse no amor, alguns usuários apropriam-se do espaço de conversação para flertar, jogar galanteios como "sou o seu homem ideal", "a mulher dos seus sonhos está aqui" e até mesmo trocar telefones. Dessa forma, práticas de conquista, flerte e romance, tipicamente românticas, nem de longe foram abandonadas em função das transformações tecnológicas. Propagar tais premissas sem estudos empíricos endossa o levantamento bibliográfico feito (FERNANDES; ALMEIDA, 2018), que comprova que pouco é estudado sobre o amor romântico.

Dito isso, a manifestação do (des)interesse no amor romântico levou-nos a refletir sobre o amor em tempos de aplicativos. Se o amor romântico é tido como uma prática social que sofreu modificações ao longo do tempo, não seria apropriado problematizá-lo na contemporaneidade? Em outras palavras, valores como fidelidade, compromisso, lealdade, entre outros atrelados ao sentimento de solidez característico do amor romântico, consequentemente, passam por um processo de reconfiguração. Portanto, isso precisa ser considerado para que possamos identificá-lo, estudá-lo e compreendê-lo. Leitores atentos podem dizer que os movimentos feitos por Giddens (1993) e Bauman (2004) exemplificam esse processo de transformação. No entanto, ao desenvolverem o amor confluente e amor líquido, respectivamente, ambos se afastam da proposta de estudar o amor romântico, uma vez que o utilizam como uma matriz para o nascimento de novas modalidades de relações afetivas, alvos de seus interesses. E se novas modalidades surgem, as anteriores parecem não ter tanto interesse ou espaço. 0 amor romântico serve, assim, apenas, como um parâmetro para evidenciar que as coisas não são mais como antes, algo que a 
reclamação/lamentação dos usuários endossa. Por outro lado, se o interesse dos usuários pelo amor romântico ainda persiste, mesmo que de modo desinteressado e recalcado, temos evidências de que ele ainda tem espaço na atualidade. A frustração pode ser explicada por não considerarmos que esses valores não se dão nos mesmos termos que antes, afinal, as demandas atuais são distintas e múltiplas.

Como nos diz Braden (1982), precisamos avaliar o amor romântico e suas experiências como elas de fato se mostram. Se as tecnologias desempenham papel importante, precisamos efetivamente considerá-las. Se os valores são reconfigurados, precisamos efetivamente considerá-los. Essas são diretrizes que demandam estudos os quais certamente guiarão trabalhos futuros.

\section{Referências}

AMARAL, O. C. Ela: o amor nos filmes e pelos filmes. Lumina, Juiz de Fora n. 1, v. 11, 2017.

BARDIN, L. Análise de conteúdo. Lisboa: Edições 70, 2004.

BOYD, D. Social network sites as networked publics: affordances, dynamics, and implications. In: PAPACHARISSI, Zizi (ed.). Networked self: identity, community, and culture on social network sites. Routledge, 2010. p. 39-58.

BRANDEN, N. A psicologia do amor romântico. Rio de Janeiro: Imago, 1982.

BAUMAN, Z. Amor líquido: sobre a fragilidade dos laços humanos. Rio de Janeiro: Jorge Zahar, 2004.

CASTRO, J. C. L. 0 amor virtual como instância de empreendedorismo e de reificação. In: Galaxia, São Paulo, n. 27, p. 72-84, jun. 2014.

FERNANDES, R.; ALMEIDA, B. 0 amor em tempos de comunicação digital: um balanço das pesquisas em periódicos brasileiros. In: ENCONTRO REGIONAL SUDESTE DE HISTÓRIA DA MÍDIA, 5., 2018, Belo Horizonte. Anais eletrônicos... Belo Horizonte: ALCAR, 2018.

FERNANDES, R. Seu amor de verdade: uma análise de conteúdo sobre a percepção do amor na Fanpage do aplicativo Par Perfeito. In: CONGRESSO DE CIÊNCIAS DA COMUNICAÇÃO NA REGIÃO SUDESTE, 23., 2018, Belo Horizonte. Anais... Belo Horizonte: Intercom Sudeste, 2018.

GIDDENS, A. A transformação da intimidade, sexualidade, amor \& erotismo nas sociedades modernas. São Paulo: Editora da Universidade Estadual Paulista, 1993. 
KRIPPENDORF, K. Content analysis, an introduction to its methodology. 3. ed. Thousand Oaks: Sage, 2012.

MAIA, J; BIANCHI, E. Tecnologia de geolocalização: Grindr e Scruff redes geosociais gays. Logos, Rio de Janeiro, v. 2, n. 24, jun./dez. 2014.

PARPERFEITO. [Página oficial no Facebook]. c2018.

RECUERO, R. Redes sociais na internet. Porto Alegre: Sulina, 2009.

RÜDIGER, F. 0 amor e a mídia: problemas de legitimação do romantismo tardio. Porto Alegre: Ed. UFRGS, 2013.

\title{
The (dis)interest in romantic love in times of dating applications.
}

\begin{abstract}
The impact of dating applications on the lives of its users has led to the understanding that solidity, security and monogamy, the basic values of romantic love, are fragmented by the technological change and the unbridled individualization. This article aims to explore the lack of interest of dating apps users in long-term relationships. For this purpose, it performs a content analysis of the comments posted in the campaign "Seu amor de verdade" made by the app "Par Perfeito" on its Facebook fanpage. As mediators of individual interests, the study revealed that users show a veiled interest in pursuing this type of relationship through expressing regrets or discouragement.
\end{abstract}

\section{Keywords}

Disinterest. Romantic love. Content analysis. Par Perfeito. Facebook.

Recebido em 13/01/2018

Aceito em 16/06/2018 